\title{
QUALITATIVE RESEARCH Practices and Challenges
}

\section{EDITORS \\ ELIZABETH M. POPE CATARINA BRANDÃO CEDRIC G. SANDERS NURIA FABRELLAS}

(17) ludomedia 


\section{(Im)}

ludomedia

\section{DATASHEET}

New Trends in Qualitative Research | Vol. 6 (2021)

Títle: Qualitative Research: Practices and Challenges

Authors: Afke Kerkstra; Ana Eva Arriscado; Carla Nascimento; Cristina Baixinho; Cristina Monteiro; David Loura; Elisabete Pinto da Costa; Héloïse Haliday; Isa Félix; Izabela Ślęzak; Jakub Niedbalski; João Rosado; Lise Demailly; Mara Pereira Guerreiro; Margarida Alves; Melissa Fernandes; Nadia Steils; Nienke Moernaunt; Pedro Teixeira; Stephen Holmes.

\section{Editors}

Elizabeth M. Pope

Catarina Brandão

Cedric G. Sanders

Nuria Fabrellas

\section{Editorial Committee}

Conceição Oliveira

Fábio Freitas

Sandra De Pinho

Sónia Mendes

\section{Publisher}

Ludomedia

Rua Centro Vidreiro, 405

São Roque

3720-626 Oliveira de Azeméis

Aveiro - PORTUGAL

e-mail // info@ludomedia.pt

web // www.ludomedia.pt

ISSN: $2184-7770$

ISBN: 978-989-54759-7-1

DOI: https://doi.org/10.36367/ntqr.6.2021 


\section{Editorial Team}

Chief Editor: António Pedro Costa, University of Aveiro - Portugal

\section{Editors}

Fábio Freitas, Politécnico de Leiria e Ludomedia - Portugal (Coordinator)

Arceli Rosario, Adventist International Institute of Advanced Studies - Philippines

Catarina Brandão, Faculdade de Psicologia e de Ciências da Educação da Universidade do Porto - Portugal

Cedric Glenn Sanders, University of Georgia - USA

Cristina Baixinho, Escola Superior de Enfermagem de Lisboa - Portugal

Elizabeth M. Pope, University of West Georgia - USA

Ellen Synthia Fernandes de Oliveira, Universidade Federal de Goiás - Brazil

María Cruz Sánchez, Universidade de Salamanca - Spain

\section{Editorial Board}

Ana Isabel Rodrigues (IPB, Portugal)

António Moreira (UA, Portugal)

Cleoneide Oliveira (CUEC, Brazil)

Emiko Yoshikawa Egry (USP, Brazil)

Isabel Pinho (UA, Portugal)

José Luís Carvalho (UNEX, Spain)

Lucimara Fornari (USP, Brazil)

Martin Tolich (UO, New Zealand)

\author{
Mercedes González Sanmamed (UDC, Spain) \\ Paulo Alexandre de Castro (UFG, Brazil) \\ Ricardo Luengo (UNEX, Spain) \\ Rodrigo Arellano Saavedra (UCM, Chile) \\ Ronaldo Nunes Linhares (UNIT, Brazil) \\ Susana Sá (IESF, Portugal) \\ Safary Wa-Mbaleka (AUA, Kenya) \\ Teresa Alzás (UNEX, Spain)
}

Ludomedia edits, publishes, and markets Qualitative Research books. Its editorial catalog includes a wide range of publications, which focus on topics such as qualitative data analysis with software support, data analysis techniques, research paradigms, among others. Each project involves researchers and authors with different experiences, exploring various research and development methodologies. The partnerships established with leading Universities have allowed the development of excellent content, reflecting the best that is done in terms of scientific research at an international level.

Copyright () Ludomedia 


\section{Scientific Committee}

António Moreira, University of Aveiro - Portugal

Andrius Puksas, Mykolas Romeris University - Lithuania

Bruna Helena Mellado, Federal University of Uberlândia - Brazil

Carla Galego, CeiED - Interdisciplinary Research Centre for Education and Development - Portugal

Catarina Brandão, Faculdade de Psicologia e de Ciências da Educação da Universidade do Porto - Portugal

Cecília Guerra, University of Aveiro - Portugal

Cedric Sanders, University of West Georgia - United States

Daniela Schiek, University of Hamburg - Germany

Elizabeth M. Pope, University of West Georgia - United States

Fatima Mendes Marques, ESEL - Lisbon School of Nursing - Portugal

Filomena Gaspar, ESEL - Lisbon School of Nursing - Portugal

Grzegorz Bryda, Jagiellonian University - Poland

Helena Ostrowicka, Universty of Kazimierz Wielki - Poland

Helder Pereira, University of the Azores - Portugal

Helga Rafael Henriques, ESEL - Lisbon School of Nursing - Portugal

Inês Amaral, Miguel Torga Higher Institute - Portugal

Izabela Ślęzak, University of Lodz - Poland

Katrin Niglas, Tallinn University - Estonia

Lia Oliveira, University of Minho - Portugal

Maria José Brites, Lusófona University of Porto - Portugal

Mario Cardano, University of Turino - Italy

Marta Romero-García, University School of Nursing University of Barcelona - Spain

Miguel Serra, ESEL - Lisbon School of Nursing - Portugal

Rachid Bendriss, Weill Cornell Medicine-Qatar

Radek Vorlíček, University of Hradec Králové - Czechia

Rosalind Edwards, University of Southampton - United Kingdom

Rui Vieira, University of Aveiro - Portugal

Silvia Caldeira, Catholic University of Portugal- Portugal

Teresa Cardoso, University Aberta - Portugal 


\section{Preface}

This second volume of 'New Trends in Qualitative Research: Practices and Challenges" includes selected papers presented at the 5th annual World Conference on Qualitative Research (WCQR) held virtually from 20-22 January 2021. There are 8 chapters in this volume: four report on qualitative studies, three are literature reviews and one is a review of digital tools for qualitative analysis.

Although research, teaching, and learning has largely moved online since early 2020 when the global COVID-19 pandemic began to take hold, the chapters in this volume illustrate the range of qualitative research being undertaken around the world despite the challenging times we have faced. In particular are the range of methodological contexts and analytic methods discussed in this volume. Two types of literature review are presented - integrative and scoping. The use of theory in qualitative research and the role of theoretical frameworks is discussed. Three chapters report on the use of thematic analysis but in quite different ways: multi-disciplinary thematic analysis, combining thematic analysis of interview transcripts with qualitative experiments, and the use of themes in presenting results of a scoping review. One chapter employs Interpretive Phenomenological Analysis (IPA), and another a mixed-methods design. One chapter presents an in-depth reflexive account of undertaking research, and others also reflect on methodological process in various ways. In addition, one chapter discusses analysis tactics by focusing on digital tools for qualitative analysis. Across this variety in methodological discussion is also the range of substantive topics discussed - including mental health, teaching and learning, and nursing care - and the countries in which the authors are undertaking their research - France, Portugal, and the UK among others. As such, this volume, like its predecessor, champions the breadth and depth of the field of qualitative research.

Chapter 1 by Jakub Niedbalski and Izabela Ślęzak, "Discovering CAQDAS - what can be helpful for a novice user of computer aided qualitative data analysis software?" presents a review of a selection of freely available digital tools designed to facilitate the analysis of qualitative data, focusing on their functionalities and utility assets. The programs discussed are grouped into those designed for working with textual materials (OpenCode, WeftQDA, CATMA and Coding Analysis Toolkit (CAT)), those designed for working on audio and video materials (Stories Matter, ELAN and Transcriber), and those designed for developing concept maps (CmapTools and MindMaster). The authors' intention with their review is to open up understandings of the range of options available beyond proprietary products that are more commonly discussed. In addition to describing some of the features of the selected tools, they offer guidance for choosing between tools, and raise potential affordances and limitations of using digital tools for qualitative analysis that they suggest should be considered before using them.

Chapter 2 by Nienke Moernaut, "Listening Between the Lines: How a Theoretical Framework Prevents Superficial Analysis in Qualitative Research," discusses the use of theory in qualitative research, illustrating how theoretical frameworks can lead to more in-depth analysis. Moernaut's discussion is framed by the continued dominance of quantitative research and the resulting pursuit of objectivity in qualitative analysis and interpretation by many qualitative researchers. Through discussion of their own research (experiences of the negative symptoms in psychosis using Interpretive Phenomenological Analysis (IPA) of in-depth interviews with 12 patients with psychosis) the author argues that use of theoretical frameworks at appropriate stages of an analysis can lift an analysis from mere summary to deeper understandings and interpretations. Moernaut contends that the pursuit of quantitative conceptions of objectivity are not only flawed, but can lead to qualitative researchers avoiding 'real' interpretation for fear of unwarranted critiques of bias.

Chapter 3 by Nadia Steils, "Qualitative Experiments for Social Sciences," discusses the usefulness of qualitative experiments based on combining quantitative and qualitative validity criteria by describing and discussing their combination of an open qualitative approach and a structured and controlled experiment. Steils first presents the theoretical context, highlighting the characteristics of qualitative experiments and discussing qualitative and quantitative validity criteria and techniques. The goals are described, focusing on the benefits and risks of qualitative experiments and providing methodological recommendations based on different validity criteria, and the methods employed are outlined - three studies including in-depth interviews preceded by qualitative experiments with interviews analysed using thematic analysis and the findings compared with those of the qualitative 
experiments. They conclude by discussing the value and limitations of qualitative experiments in terms of their value in exploring and identifying patterns, processes and behaviours in alternative ways.

Chapter 4 by Stephen Holmes, "It Doesn't Rain it Pours' - Reflections on Fieldwork in The Academic Year 2019/20," presents a personal reflective and reflexive account of the challenges faced by postgraduate researchers in the UK during the 2019-2020 academic year. Three key situations that gave rise to challenges in gaining access to research participants are discussed: industrial action across the higher education sector in the UK; regional rial network industrial strikes, and the global COVID-19 pandemic. Framed by an interpretivist epistemology, Holmes reflects on the impact of these challenges on the study into teaching innovation in the UK higher education sector in the UK. The account presented in this chapter is methodologically and personally reflexive as Holmes has a "conversation with oneself" - reflecting both on the impacts on the research process that the barriers to access gave rise to, and on the emotions the situations and resulting experiences created for the author personally. The adaptation of methods and the technologies used to undertake fieldwork whilst in-person data collection was not possible are described, and the problems encountered are discussed. The chapter concludes with a reflection on the limitations of reflection.

Chapter 5 by Héloïse Haliday and Lise Demailly, "Going Beyond a Conflict of Approaches in Psychiatric Care: The Perks of Interdisciplinary Research," presents and reflects on the process and findings of their qualitative study exploring the interactions between mental health care professionals and service-users in the French public psychiatry system. After describing the psychiatric care system in France to provide the research context, the authors outline their overarching research objectives. First, to reveal professional and organizational issues in mental health care and to understand the construction of professional cultures in terms of consistency, resistance to change, and their potential for evolution. Second, to detail their study methodology: an ethnographic framework in which qualitative data were collected via in-depth interviews and observations and were interpreted using multi-disciplinary thematic analysis. As well as presenting their findings that reveal the eclectic and heterogeneous nature of care practices, the authors discuss the extent to which research findings can be "enough," by reflecting on whether unsurprising results "matter," the methodological obstacles they faced, and the extent to which they were "worth the trouble."

Chapter 6 by Christina Monteiro, Joao Rosado, Pedro Teixeira, and Melissa Fernandes, "From Emergency to the community: Nursing care that promotes safe transition of the person whit increased vulnerability," presents the findings of an integrative literature review of nursing care promoting safe transitions between emergency departments and the community in Portugal. The authors place their work in the context of historic and projected demographic changes in Portugal, that are resulting in an ageing population with changing healthcare needs and likely subsequent pressures on emergency and community care. Their literature review seeks to identify risk factors for readmission to emergency departments and the nursing care practices that promote safe transitions between emergency departments and the community amongst elderly populations (defined in Portugal as those aged 65 and over). The methodology for selecting the articles for review is outlined (based on PRISMA recommendations) and the process of selecting the seven articles that were included from the 98 that were identified from publication databases is illustrated. The findings of these articles are summarised, compared and discussed.

Chapter 7 by David Loura, Ana Eva Arriscado, Afke Kerkstra, Carla Nascimento, Isa Félix, Mara Pereira Guerreiro, and Cristina Baixinho, "Interprofessional Competency Frameworks in Health to Inform Curricula Development: Integrative Review," seeks to answer the following question: "What are the competency frameworks that support learning outcomes-based curricula for interprofessional education in health?" The authors present the context for their integrative literature review, its methodology and the results. The review is part of a larger research study - the Train4Health project - surveying the landscape of interprofessional competency frameworks (ICFs) in health. The authors provide an introduction to this context before outlining the integrative review methodology conducted over a seven month period and which followed an established six phased protocol that they describe and illustrate. 
They present the results of the review, highlighting that they identified only four ICFs that support the development of curricula in the specific area of competencies. They reflect on this finding both in terms of the limitations of their own work and in the context of the usefulness of competency frameworks.

Chapter 8 by Margarida Alves and Elisabete Pinto da Costa, "Framing Conflict Mediation in the Context of Teacher Training: A Scoping Review of the Literature Between 2000 and 2020," presents the methodology and findings of their scoping review that sought to answer the following question: "What can we learn from research on conflict mediation in schools in the context of initial teacher training published in EBSCOhost and Scopus databases?" The authors present an overview of the theoretical background to the review, outlining why the focus on conflict mediation in the context of teacher training is warranted. The review methodology is described, including its purpose, focus and research question, search and selection criteria, time-scale and five-stage analysis process. Seventy studies were initially identified and seven empirical studies were included in the review after exclusion criteria were applied. Descriptive results and thematic findings of the seven included studies are presented and discussed. The authors highlight key insufficiencies in how conflict mediation in schools and its impact on teacher training have been empirically researched over the past 20 years.

The chapters presented in this volume demonstrate the range and quality of research that scholars around the world have been undertaking despite the challenges presented by the global COVID-19 pandemic during the past year. Working in different contexts, with different methodological foci and using different analytic techniques, these chapters showcase their work and illustrate the standard of research presented at the 5th World Congress on Qualitative Research. They provide both insights and exemplars that will be useful to qualitative and mixed-methods researchers around the globe.

March 4th, 2021

Christina Silver, PhD, FAcSS

University of Surrey \& Qualitative Data Analysis Services, UK 


\title{
Introduction \\ In the Face of Uncertainty: Opportunities, Challenges, and Solutions for Qualitative Researchers
}

\begin{abstract}
The ebook series, "New Trends in Qualitative Research: Practices and Challenges" began in July of 2020 with the release of its first volume. In the United States, this was a mere five months after the country began to encourage practices such as social distancing, shelter-in-place, and wearing masks due to the outbreak of COVID-19. In March 2020, the state of Georgia held its first (and at the time of this writing, only) lockdown to help stop the spread of the virus. In most European countries, restrictive measures have been adopted since January 2020, with lockdowns being somewhat frequent, according to the number of infections in each country at a given moment, and social distancing as a norm. Masks, alcohol gel, respiratory etiqueta, and walking on the right side of the streets are all now part of our lives. Now, with countries still being affected (some more than others), hope is in all our minds, due the development of several vaccines. At the same time, new variants of the virus have been discovered and uncertainty has become the new normal. Side by side with hope. And trust in science.
\end{abstract}

As we write this introduction to volume six of New Trends in Qualitative Research, we believe it is fundamental to refer to this current context. What else should be expected from the editors of a virtual space which gives voice to qualitative research? This international pandemic has changed the lives of many. Individuals are working from home, finding ways to share the burdens of their personal and family lives with partners and spouses so that they may continue to be productive in their professional pursuits. For those who cannot work from home, ways to embrace health safety, social distancing, and yet still continue to work remain major concerns.

Even without the complexity an international pandemic adds, the Academy is full of unique challenges related to teaching, scholarship, and service. For teaching, many institutions have converted face-to-face courses online or follow a model of dual modality offering both online and face-to-face learning options within a single course, as we (at the same time) try to understand the impact of these changes in the teaching - learning process (e.g., Arora \& Srinivasan, 2020). For many faculty, the need to learn new teaching methods has imposed additional stressors in an increasingly stressful environment. Faculty already experienced in online learning are among the lucky, sharing their knowledge and skills by mentoring other faculty seeking to learn and rise to their new challenges.

Research and scholarship have also begun to move online. One such example is in the rise of virtual conferences. The World Conference on Qualitative Research (WCQR), from which we elicited manuscripts for this ebook, hosted an entirely online conference from January 20-22, 2021. Conferences for organizations such as the American Educational Research Association, the International Congress of Qualitative Inquiry, NVivo through QSR International, and The Qualitative Report have done the same. Even more encouraging to scholars enjoying the new trend of virtual conferences is the rise of permanently online conferences such as the Virtual Conference for Qualitative Inquiry. The field of qualitative research is not alone in this change of modality. There is a rise in published articles in a variety of disciplines that look at this advancement in the academy (e.g. Reinhard, 2021; Roos, 2020; Yu-Ju, 2021). While many will undoubtedly return to in-person formats with the end of COVID-19, it is possible that just as many will maintain an online component.

Of course there are differences regarding the accessibility of researchers from different places around the globe regarding technology (namely connections and hardware), but many researchers were able to attend several international conferences in the same year, with far less funding. And, by doing so, we could make our work known to researchers from other contexts, in what may translate a greater democracy in access to the dissemination of science. Human beings need human interaction and online conferences are very limited at this level. Nonetheless, this experience allowed many researchers to experience new benefits that should be considered as a way to overcome differences that researchers have in access to resources.

As Mills and Birks (2014) state "The first building block of a qualitative research study is writing a research question that works" (p. xv). Since COVID-19 entered our lives, it seems the question that emerged as inevitably (particularly) to qualitative researchers, was: How to conduct my research 
without being with the people, in their contexts? Being faithful to the nature of qualitative research, qualitative researchers embraced the pandemic context as a focus of research. We could see this in several papers presented at WCQR 2021.

Consider, for example, the work conducted in Costa Rica by Patricia Estrada, Lady Mora and Estefanía Hidalgo (Estrada et al., 2021). While developing a project in a rural community, they were forced to look at their research design and adapt to the circumstances in a dynamic balance between the possible (e.g., technological resources available) and the desired. The same is seen in the work by Ana Gama, Patrícia Marques, Bernardo Vega Crespo, José Ortiz-Segarra and Sónia Dias (Gama et al., 2021). While conducting focus groups in the context of an international project about cervical cancer screening, the team was able to see the particularities of turning the method online. They mentioned the need to reduce the number of participants, the difficulty to access non verbal behaviors (and verbal behaviours in the physical events, due to masks), the low self expression of participants (for being at home with other family members) and the impact of technology (being or not proficiency, ease, etc.).

Returning to Mills and Birks (2014), we are confident to say that, albeit still living a crises that may take us a long time to overcome, given that its social and economic impact is just beginning, qualitative researchers of different fields have shown themselves to be up to the challenge in several ways. They have been able to look at themselves, and reflect on their own practices and experiences as researchers. This is happening for instance, through the work of Melanie Nind, Robert Meckin, and Andy Coverdale, from the National Centre for Research Methods, in the UK, who have been giving online Workshops (e.g., "Changing Research Practices for Covid-19") where researchers are called up to look at themselves and their practices as they are impacted by the present context. Qualitative researchers have also been able to innovate, as the Asian Qualitative Research Association (AQRA) has shown at WCQR 2021, with the Panel Discussion "Data Collection Methods Through Online Modalities", where David Lumowa, Arceli Rosario, Pavel Zubkov and Safary WaMbaleka, presented and discussed how in-depth interviews, observation, and focus group may happen mediated by technology, but also arts-based research (Lumowa et al., 2021). This latter emerged, to some of us, as a tremendously powerful method to conduct research today, namely participatory research.

While the use of digital technologies in qualitative research is not a new topic (Deakin \& Wakefield, 2013; Morgan \& Symon, 2004; Selz, 2016), it seems that digital teaching, research, and scholarship is more paramount than ever before. In a social environment where academics work through screens with one another and face-to-face interactions are minimal, they find ways to use digital technologies to their advantage (Paulus \& Lester, 2021). The process of editing this ebook embraced the use of these technologies from beginning to end. Working in the U.S., Portugal, and Spain, we (the editors) work within the midst of the necessity to move scholarship to an online platform. The challenge of working from home, with colleagues across the world, during an international pandemic, is unique to our time. Never before has such a pandemic impacted the world during the digital age.

As members of the Editorial Team, we have worked online since the beginning of the ebook series, so this was not new to us. As in the first ebook, this was an exciting and fun process. It allowed us to add another two editors, enriching our own international academic community. Along the way we managed the natural challenges of these processes, as we had the privilege to work with great reviewers and authors, in a collaborative process that allowed for immense learning. However, this time around, we had to work with our families at home, as each member of the household juggled different roles - being in a relationship or alone, being a parent, missing family, and mourning for loved ones. It is always a joy to see a new volume of NTQR, a project we embraced since its beginning. But this volume feels a bit different, as it is a product that we managed to produce in particularly difficult times.

We present here volume six of "New Trends in Qualitative Research: Practices and Challenges." Putting this ebook together was a process that was the epitome of the practice of using digital technologies in qualitative scholarship and the challenges that lie within. It has been a rewarding and difficult experience.

Elizabeth M. Pope ${ }^{1}$ and Catarina Brandão ${ }^{2}$ ${ }^{1}$ University of West Georgia, USA ${ }^{2}$ University of Porto, Portugal 


\section{References}

Arora, A. K., \& Srinivasan, R. (2020). Impact of pandemic COVID-19 on the teaching - learning process: A study of higher education teachers. Indian Journal of Management, 13(4), 43-56. http://dx.doi.org/10.17010/pijom\%2F2020\%2Fv13i4\%2F151825

Deakin, H., \& Wakefield, K. (2013) Skype interviewing: Reflections of two PhD researchers. Qualitative Research, 14(5), 603-616. https://doi.org/10.1177/1468794113488126

Estrada, P. L., Mora, L. F., \& Hidalgo, E. P. (2021, January 21-23). Reflections about conducting qualitative research during pandemic times as part of an extension project in the rural community of San Ramón de La Virgen de Sarapiquí, Costa Rica [Paper presentation]. World Conference on Qualitative Research, Online.

https://www.youtube.com/watch?v=pwDJfzRlfHU\&list=PLkEhUdpQi4keO_-am2z4hTUnAaA20U6W\&index=14

Gama, A., Marques, P., Crespo, B. V., Ortiz-Segarra, J., \& Dias, S. (2021, January 21-23). Conducting qualitative health research in times of COVID-19 pandemic: Insights from ELEVATE focus group study about cervical cancer screening among hard-to-reach women [Paper presentation]. World Conference on Qualitative Research, Online. https://www.youtube.com/watch?v=3NkWspBgqL4\&list=PLkEhUdpQi4keO_-am2z4hTUnAaA20U6W\&index $=25$

Mills, J., \& Birks, M. (Eds.). (2014). Qualitative methodology. A practical guide. Sage.

Morgan, S. J., \& Symon, G. (2004). Electronic interviews in organizational research. In C. Cassell \& G. Symon (Eds.), Essential guide to qualitative methods in organizational research (pp. 23-33). Sage.

Paulus, T., \& Lester, N. (2021). Doing research in a digital world. Sage.

Reinhard, D., Stafford, M. C., \& Payne, T. C. (2021). COVID-19 and academia: Considering the future of academic conferencing. Journal of Criminal Justice Education. Advanced online publication. https://doi.org/10.1080/10511253.2020.1871047

Roos, G., Oláh, J., Ingle, R. C., Kobayashi, R. D., Feldt, M. E. (2020). Online conferences - toward a new (virtual) reality. Computational and Theoretical Chemistry, 1189, Article e112975. https://doi.org/10.1016/j.comptc.2020.112975

Seitz, S. (2016). Pixilated partnerships, overcoming obstacles in qualitative interviews via skype: A research note. Qualitative Research, 16(2), 229-235. https://doi.org/10.1177/1468794115577011

Yu-Ju, L., Gupta, K. C., Tai-Yi, H., Chelliah, S., \& Spector, J. M. (2021). Organizing and hosting virtual PPTELL 2020 during the COVID-19 pandemic. Journal of Educational Technology and Society, 24(1), 64-74. https://www.jstor.org/stable/26977857 
EXPLORING CAQDAS - HOW TO SUPPORT A NOVICE USER OF COMPUTER AIDED QUALITATIVE DATA ANALYSIS SOFTWARE

Izabela Ślęzak; Jakub Niedbalski.

LISTENING BETWEEN THE LINES: HOW A THEORETICAL FRAMEWORK PREVENTS SUPERFICIAL ANALYSIS IN QUALITATIVE RESEARCH

Nienke Moernaut.

QUALITATIVE EXPERIMENTS FOR SOCIAL SCIENCES

Nadia Steils.

IT DOESN'T RAIN IT POURS-REFLECTIONS ON FIELDWORK IN THE ACADEMIC YEAR 2019/20

Stephen Holmes

GOING BEYOND A CONFLICT OF APPROACHES IN PSYCHIATRIC CARE: THE PERKS OF INTERDISCIPLINARY RESEARCH

Héloïse Haliday; Lise Demailly

\section{LITERATURE REVIEW}

FROM EMERGENCY TO THE COMMUNITY: NURSING CARE THAT PROMOTES SAFE TRANSITION OF THE PERSON WITH INCREASED VULNERABILITY

Cristina Monteiro; João Rosado; Melissa Fernandes; Pedro Teixeira.

INTERPROFESSIONAL COMPETENCY FRAMEWORKS IN HEALTH TO INFORM CURRICULA DEVELOPMENT: INTEGRATIVE REVIEW

Afke Kerkstra; Ana Eva Arriscado; Carla Nascimento; Cristina Baixinho; David Loura; Isa Félix; Mara Pereira Guerreiro.

FRAMING CONFLICT MEDIATION IN THE CONTEXT OF TEACHER TRAINING: A SCOPING REVIEW OF THE LITERATURE BETWEEN 2000 AND 2020

Elisabete Pinto da Costa; Margarida Alves 